\title{
The Archaea Community Associated with Lava-Formed Gotjawal Forest Soil in Jeju, Korea
}

\author{
Jong-Shik Kim ${ }^{1}$, Man-Young Jung2, Keun Chul Lee ${ }^{3}$, Dae-Shin Kim ${ }^{4}$, Suk-Hyung Ko ${ }^{4}$, \\ Jung-Sook Lee ${ }^{3}$, Sung-Keun Rhee ${ }^{2}$ \\ ${ }^{1}$ Gyeongbuk Institute for Marine Bioindustry, Uljin, Republic of Korea \\ ${ }^{2}$ Department of Microbiology, Chungbuk National University, Cheongju, Republic of Korea \\ ${ }^{3}$ Korea Research Institute of Bioscience and Biotechnology, Daejeon, Republic of Korea \\ ${ }^{4}$ Research Institute for Hallasan, Jeju, Republic of Korea \\ Email: ${ }^{\text {soilmicrobiome@gmail.com }}$
}

Received 22 April 2014; revised 27 May 2014; accepted 23 June 2014

Copyright @ 2014 by authors and Scientific Research Publishing Inc.

This work is licensed under the Creative Commons Attribution International License (CC BY).

http://creativecommons.org/licenses/by/4.0/

(c) (i) Open Access

\section{Abstract}

The abundance and diversity of archaeal assemblages were analyzed in soils collected from Gyorae Gotjawal forest, Jeju, Korea. Gotjawal soil refers to soil derived from a lava-formed forest, characterized by high organic matter content, fertility, and poor rocky soil. Using domain-specific primers, archaeal 16S rRNA gene sequences were PCR amplified for clone library construction, and a total of 185 archaeal clones were examined. The archaeal clones were affiliated with the phyla Thaumarchaeota $(96.2 \%)$ and Euryarchaeota $(3.8 \%)$. The most abundant thaumarchaeal group (90.3\% of the clones) was the group I.1b clade, which includes soil ammonia-oxidizing archaea. The unique characteristics of Gotjawal soil, including basalt morphology, vegetation, and groundwater aquifer penetration, may be reflected in the archaeal community composition. Further study is necessary to understand the unique factors of Gotjawal soils that influence archaeal abundance, composition, and diversity.

\section{Keywords}

Archaea, Gotjawal Soil, 16S rRNA Gene, Phylogeny

\section{Introduction}

In Jeju, Korea, the word "Gotjawal” refers to any natural forest with trees that grows from basalt-flow rock in

How to cite this paper: Kim, J.-S., Jung, M.-Y., Lee, K.C., Kim, D.-S., Ko, S.-H., Lee, J.-S. and Rhee, S.-K. (2014) The Archaea Community Associated with Lava-Formed Gotjawal Forest Soil in Jeju, Korea. Journal of Agricultural Chemistry and Environment, 3, 96-102. http://dx.doi.org/10.4236/jacen.2014.33012 
the poorest soil, and forms a virtually impassable mixture of trees and undergrowth [1]. These forests are considered to represent sites of international importance because of their unique forest ecosystems and the support provided for ecological communities [2]. The Gotjawal are referred to as the "lungs of Jeju" and provide clean air in exchange for carbon dioxide, which is necessary within the ecosystem. It also functions as a roof over pristine aquifers, as well as porous rocks that purify and recharge rainwater. The Gotjawal represents a biosphere; it has an enormous biodiversity, which includes plant species of both the northern and southern hemispheres. In addition, the Gotjawal is a microclimate regulated by openings into the earth that act as breathing holes and provide water to the aquifers below [3] [4]. However, lava forests have been gradually disappearing in recent decades, with $\sim 50 \%$ having been destroyed, leaving $6 \%$ of the landmass remaining as a result of unregulated construction and urbanization [5].

The forest is crucial for replenishing the only source of water for Jeju's population of half a million, and for nursing its unique flora and fauna, which include some endangered species and other species endemic to the island. Until recently, no studies had characterized the microorganisms in the soil environments of a Gotjawal forest. Little is known about the soil microbial community or the characteristics that direct its formation [6] [7].

Here, we analyzed the abundance, composition, and diversity of archaea in Gotjawal soils using a polymerase chain reaction (PCR)-based approach. Our study will expand the understanding of soil microbial communities to include those of lava forest soils.

\section{Materials and Methods}

\subsection{Collection of Gotjawal Soil Samples}

The geographic coordinates of the sample collection site were $33^{\circ} 26.023^{\prime} \mathrm{N}, 26^{\circ} 39.46^{\prime} \mathrm{W}$ (Gyorae Natural Recreation Forest, Figure 1(a)). Samples of soil located below the lava and trees were aseptically collected using ethanol-disinfected spatulas and placed into sterile, sealable plastic bags (Figure 1(b)). Soil samples were stored in a cooler during transfer to our laboratory and then stored at $5^{\circ} \mathrm{C}$ until further processing. Prior to total DNA extraction, soil subsamples were stored at $-70^{\circ} \mathrm{C}$. Soil analysis and DNA extraction were conducted within a week of collection. Soil pH and electrical conductivity (EC) were measured in soil extracts using a 1:5 soil: water ratio. Organic matter was analyzed using the Walkey-Black method [8] and nitrate was quantified with a Kieltec auto 2400 system (Tecato AB, Sweden) at the National Instrumentation Center for Environmental Management (NICEM) in Seoul National University.

\subsection{DNA Extraction, PCR, and Cloning}

DNA was directly extracted from several soil subsamples using the FastDNA ${ }^{\circledR}$ SPIN Kit for Soil (QBiogene Inc., Vista, CA, USA) according to the manufacturer's instructions. The extracted DNA was purified using a FastPure DNA ${ }^{\mathrm{TM}}$ Kit (Takara Bio Inc., Japan) and concentrated using a Zymoclean ${ }^{\mathrm{TM}}$ Gel DNA Recovery Kit (Zymo Research Corp., Orange, CA, USA). Purified DNA from multiple subsamples was combined and used to construct the clone library. The forward and reverse primers used to amplify archaeal 16S rRNA genes were Ar4F and Ar958R [9], respectively. For clone library construction, $1 \mu \mathrm{L}$ of DNA template was placed in a $20-\mu \mathrm{L}$ reaction mixture and PCR-amplified according to conditions described previously [10]. The thermocycler conditions were $95^{\circ} \mathrm{C}$ for $5 \mathrm{~min}$; 30 cycles of $95^{\circ} \mathrm{C}$ for $45 \mathrm{~s}, 55^{\circ} \mathrm{C}$ for $45 \mathrm{~s}$, and $72^{\circ} \mathrm{C}$ for $90 \mathrm{~s}$; and a final extension step of $72^{\circ} \mathrm{C}$ for $5 \mathrm{~min}$. The amplification products were purified with a QIAquick PCR Purification Kit (Qiagen, Valencia, CA, USA). The purified PCR products were ligated into pUC118 Hinc II/BAP (Takara Bio Inc., Japan), transformed into competent Escherichia coli DH4 $\alpha$ cells (Invitrogen Corp., Carlsbad, CA, USA), and then plated on Luria-Bertani (LB) agar plates for selection of transformants. White recombinant transformants were selected and grown overnight at $37^{\circ} \mathrm{C}$ in $\mathrm{LB}$ medium containing $0.1 \mathrm{~g} \cdot \mathrm{L}^{-1}$ ampicillin. Plasmids from E. coli $\mathrm{DH} 4 \alpha$ transformants were isolated using the PureLink ${ }^{\circledR}$ Quick Plasmid Miniprep Kit (Invitrogen Corp., Carlsbad, CA, USA).

\subsection{Sequencing and Phylogenetic Analysis}

The 16S rRNA genes from the archaeal clones were sequenced using an Applied BioSystems model 3730xl automated DNA sequencing system (Foster City, CA, USA). Putative chimeric sequences were identified using Bellerophon [11] and removed from analysis. Multiple sequence alignment of 16S rRNA gene sequences was performed using the online aligner SINA using the SILVA database (http://www.arb-silva.de/aligner [12]), 


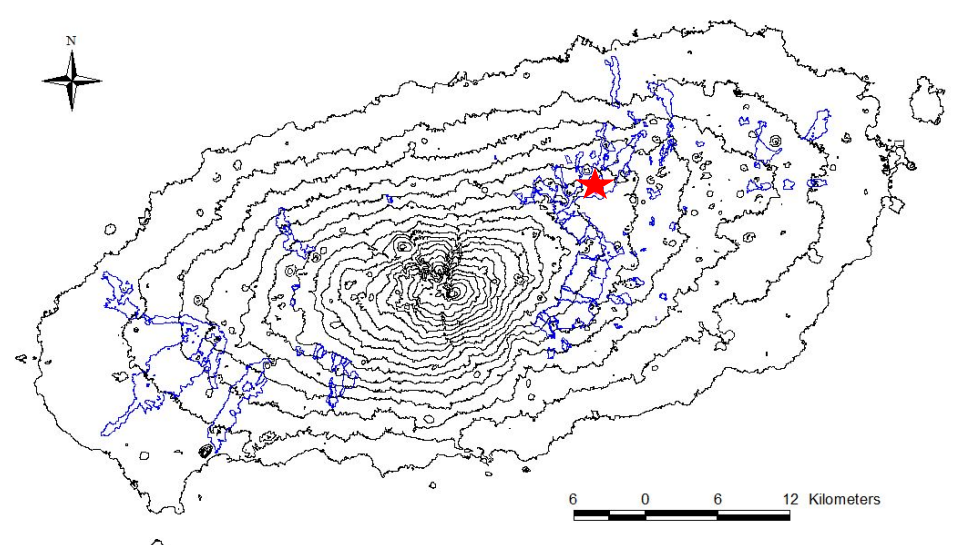

(a)

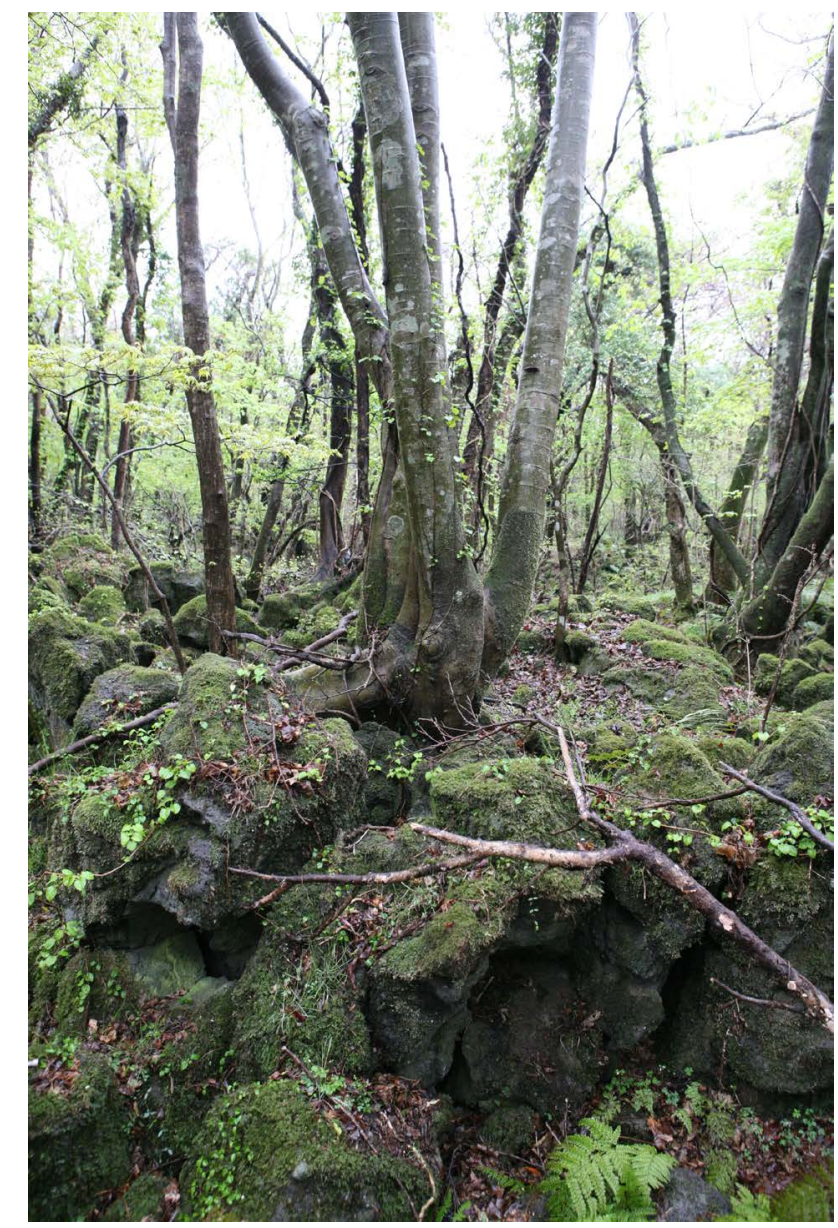

(b)

Figure 1. (a) A geologic map of Jeju Island showing the Gotjawal distribution (blue line) and sampling sites; Gotjawal forest (red star symbol); (b) Photograph of an undisturbed Gyorae Gotjawal forest (33 $26.023^{\prime} \mathrm{N}, 26^{\circ} 39.46^{\prime} \mathrm{W}$ ) in the Gyorae Natural Recreation Forest, Jeju, Korea.

which takes into consideration the secondary structure of the rRNA gene. Phylogenetic trees were constructed using the neighbor-joining method [13] with MEGA version 5.0 for Windows [14]. Evolutionary distances were calculated using the Kimura 2-parameter method [15]. Bootstrap analyses of the neighbor-joining data were conducted based on 1000 samples to assess the support for inferred phylogenetic relationships. 


\subsection{Nucleotide Sequence Accession Numbers}

All sequences were deposited in DDBJ/GenBank/EMBL under the following accession numbers: AB848738AB848922 (185 archaeal clones).

\section{Results and Discussion}

The soil samples collected from Gyorae Gotjawal had a $\mathrm{pH}$ of 4.5 , an electrical conductivity of $3.44 \mathrm{dS} \cdot \mathrm{m}^{-1}$, $34 \%$ organic matter content, and an $\mathrm{NO}_{3}{ }^{-}$concentration of $300.48 \mathrm{mg} \cdot \mathrm{kg}^{-1}$ dry soil.

Analysis of archaeal 16S rRNA gene sequences was performed with a total of 185 clones. Of them, 178 clones (96.2\%) belonged to the phylum Thaumarchaeota and 7 (3.8\%) to the phylum Euryarchaeota (Figure 2).

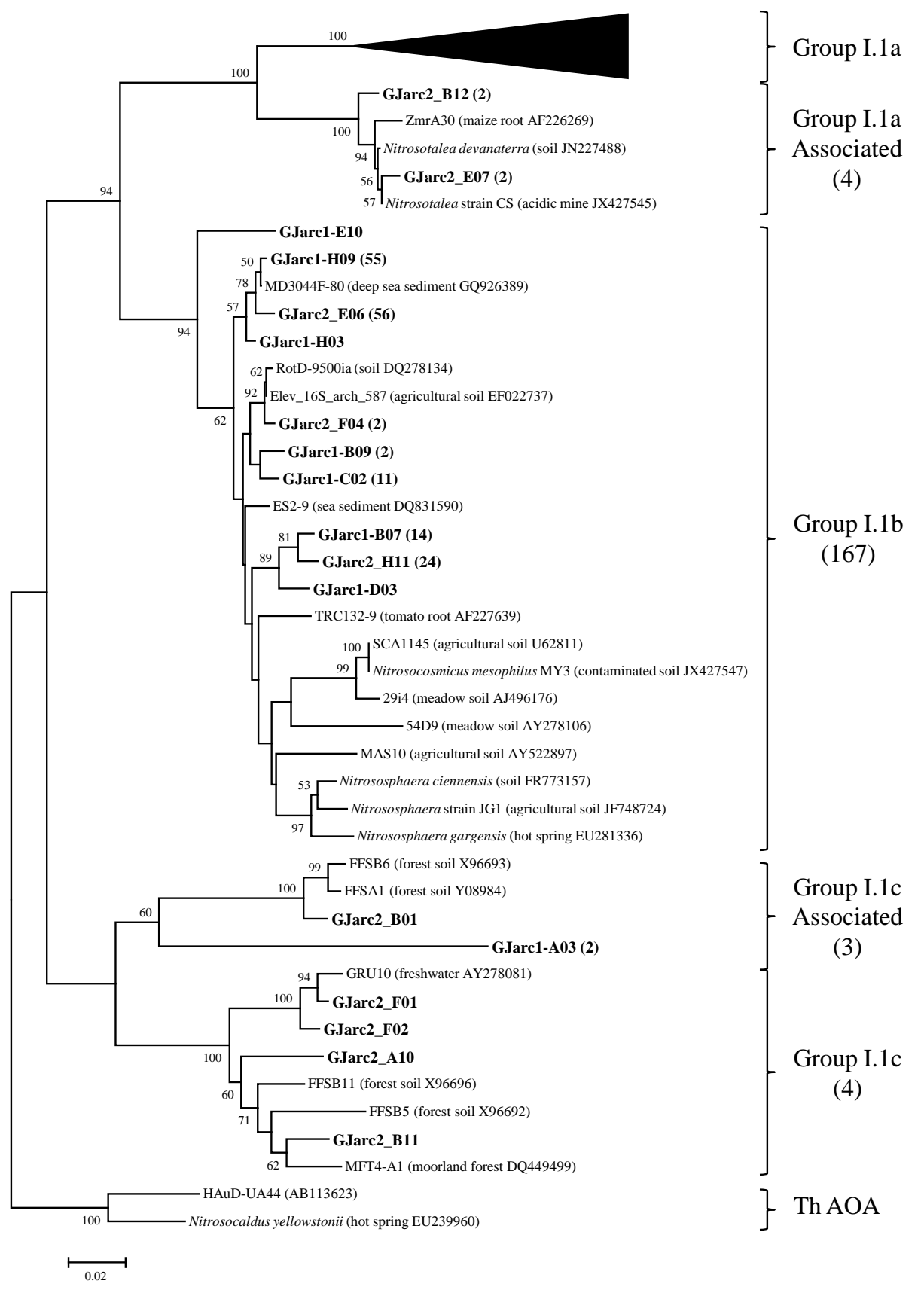




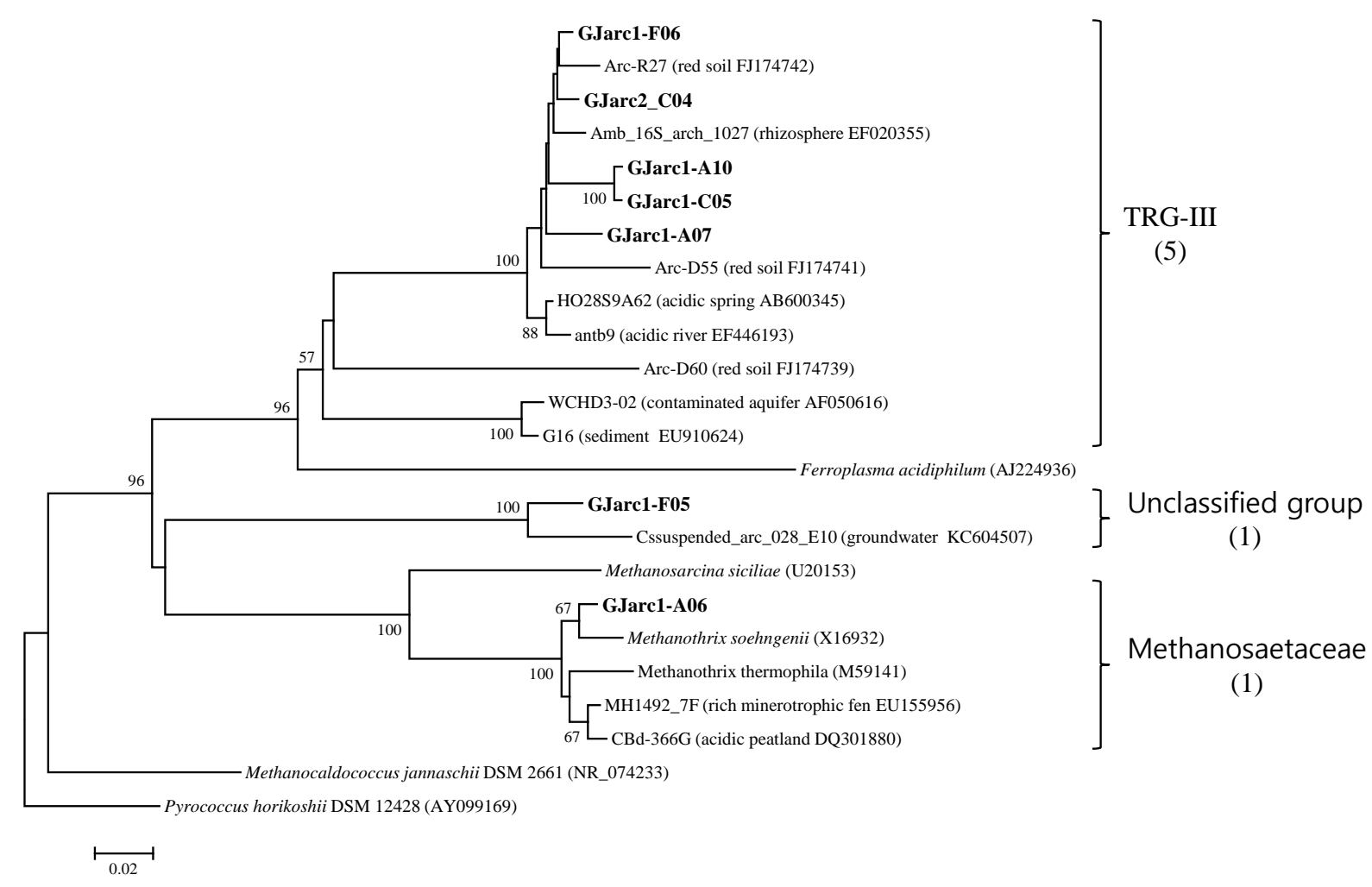

(b)

Figure 2. Phylogenetic tree of 185 archaeal 16S rRNA gene sequences from Gotjawal soil: (a) Thaumarchaeota; (b) Euryarchaeota. Bootstrap values $>50 \%$ (1000 iterations, neighbor-joining method) are shown for supported branches. The scale bar represents $2 \%$ estimated sequence divergence. The numbers in parentheses following clone names indicate the number of additional clones represented by the sequence ( $\geq 99.5 \%$ identity).

Most Thaumarchaeota clones belonged to group I.1b, which has been reported in various soils [16] and is known to include ammonia-oxidizing archaea (AOA) [4] [17]. Despite the low pH (4.5) of the lava soils, only four Thaumarchaeota clones were detected that were affiliated with the group I.1a-associated acidophilic AOA group, which includes acidophilic ammonia-oxidizing archaea [18]. Seven group I.1c, and group I.1c-associated clones were identified (Figure 2(a)). Archaeal communities in many acidic forest soil systems, including grassland pasture, moorland, and alpine soils, are dominated by the group I.1c thaumarchaeal lineage [19], although the ecological functions of this group remain unknown. Notably, thaumarchaeal group I.1b, which is frequently detected in various soil environments, was prevalent despite the low soil $\mathrm{pH}$. The group I.1a thaumarchaeal lineage, which is the most abundant in the marine environment, was not identified in the clone library (Figure 2(a)).

A total of five euryarchaeal clones belonged to Thermoplasma-related group III (TRG-III) [19]. The phylotypes in TRG-III were related to environmental clones recovered from acidic environments [20]-[22]. One euryarchaeal clone was related to methanogens of the Methanosaetaceae family (Figure 2(b)).

Most notably, clones related to AOA dominated (92.4\%) the archaeal clone library. The absence of clones of ammonia-oxidizing bacteria (AOB) and the relative abundance of archaeal amoA genes compared to bacterial amoA genes tempted us to speculate that AOA might be important players in lava forest soils. It has been proposed that pristine environments may be preferred by AOA more than by AOB, based on ecological studies of the numerical abundance of ammonia oxidizing microorganisms [23] and studies of soil AOA affinity for ammonia and oxygen [24]. There remains controversy regarding the relationship between the numerical abundance of AOA and their ecological activity [23] [25], and a mixotrophic metabolism has been proposed specifically for the soil AOA of thaumarchaeal group I.1b.

\section{Conclusion}

In conclusion, most of the archaeal clones were affiliated with thaumarchaeal group I.1B, which are related to 
nitrifying archaea. Further studies are required to fully understand their abundance, diversity and functions in soil.

\section{Acknowledgements}

We thank Jung, S.B. for assistance with soil sampling.

\section{References}

[1] Song, S.T. and Yoon, S. (2002) Lavas in Gotjawal Terrain, Jeju Island, Korea No. 1. Jocheon-Hamdeok Gotjawal Terrain. Journal of the Geological Society of Korea, 38, 377-389.

[2] Jang, Y.C. and Lee, C.W. (2009) Gotjawal Forest in Jeju Island as an Internationally Important Wetland. Journal of Korean Wetlands Society, 11, 99-104.

[3] Yang, K.S., Kim, S.B., Kim, S.Y., Lee, G.E. and Kim, W.T. (2006) Community Analysis of the Moths in the Gotjawal Terrains of Jeju Island, Korea. Journal of Ecology and Field Biology, 29, 365-379. http://dx.doi.org/10.5141/JEFB.2006.29.4.365

[4] Kim, J.G., Jung, M.Y., Park, S.J., Rijpstra, W.I., Sinninghe Damste, J.S., Madsen, E.L., et al. (2012) Cultivation of a Highly Enriched Ammonia-Oxidizing Archaeon of Thaumarchaeotal Group I.1b from an Agricultural Soil. Environmental Microbiology, 14, 1528-1543. http://dx.doi.org/10.1111/j.1462-2920.2012.02740.x

[5] Jung, S.H. (2009) Insects of Seonheul Gotjawal (Covered by a Rubble Flow) in Jeju Is. Journal of Korean Nature, 2, 175-182.

[6] Amann, R.I., Ludwig, W. and Schleifer, K.H. (1995) Phylogenetic Identification and in Situ Detection of Individual Microbial Cells without Cultivation. Microbiological Reviews, 59, 143-169.

[7] Torsvik, V., Goksoyr, J. and Daae, F.I. (1990) High Diversity in DNA of Soil Bacteria. Applied Environmental Microbiology, 56, 782-787.

[8] Nelson, D.W. and Sommers, L.E. (1996) Total Carbon, Organic Carbon, and Organic Matter. Methods of Soil Analysis Part 3-Chemical Methods, 961-1010.

[9] Jurgens, G., Glockner, F.O., Amman, R., Saana, A., Montonen, L., Likolammi, M. and Munster, U. (2000) Identification of Novel Archaea in Bacterioplankton of a Boreal Forest Lake by Phylogenetic Analysis and Fluorescent in Situ Hybridization. FEMS Microbiology Ecology, 34, 45-56.

[10] Lane, D.J. (1991) 16S/23S rRNA Sequencing. In: Stackebrandt, E. and Goodfellow, M., Eds., Nucleic Acid Techniques in Bacterial Systematics, John Wiley and Sons, New York, 115-175.

[11] Huber, T., Faulkner, G. and Hugenholtz, P. (2004) Bellerophon: A Program to Detect Chimeric Sequences in Multiple Sequence Alignments. Bioinformatics, 20, 2317-2319. http://dx.doi.org/10.1093/bioinformatics/bth226

[12] Pruesse, E., Quast, C., Knittel, K., Fuchs, B.M., Ludwig, W., Peplies, J. and Glockner, F.O. (2007) SILVA: A Comprehensive Online Resource for Quality Checked and Aligned Ribosomal RNA Sequence Data Compatible with ARB. Nucleic Acids Research, 35, 7188-7196. http://dx.doi.org/10.1093/nar/gkm864

[13] Saitou, N. and Nei, M. (1987) The Neighbor-Joining Method: A New Method for Reconstructing Phylogenetic Trees. Molecular Biology and Evolution, 4, 406-425.

[14] Tamura, K., Peterson, D., Peterson, N., Stecher, G., Nei, M. and Kumar, S. (2011) MEGA5: Molecular Evolutionary Genetics Analysis Using Maximum Likelihood, Evolutionary Distance, and Maximum Parsimony Methods. Molecular Biology and Evolution, 28, 2731-2739. http://dx.doi.org/10.1093/molbev/msr121

[15] Kimura, M. (1980) A Simple Method for Estimating Evolutionary Rates of Base Substitutions through Comparative Studies of Nucleotide Sequences. Journal of Molecular Evolution, 16, 111-120. http://dx.doi.org/10.1007/BF01731581

[16] Auguet, J.C., Barberan, A. and Casamayor, E.O. (2009) Global Ecological Patterns in Uncultured Archaea. The ISME Journal, 4, 182-190. http://dx.doi.org/10.1038/ismej.2009.109

[17] Hatzenpichler, R., Lebedeva, E.V., Spieck, E., Stoecker, K., Richter, A., Daims, H. and Wagner, M. (2008) A Moderately Thermophilic Ammonia-Oxidizing Crenarchaeote from a Hot Spring. Proceedings of the National Academy of Sciences of the United States of America, 105, 2134-2139. http://dx.doi.org/10.1073/pnas.0708857105

[18] Lehtovirta-Morley, L.E., Stoecker, K., Vilcinskas, A., Prosser, J.I. and Nicol, G.W. (2011) Cultivation of an Obligate Acidophilic Ammonia Oxidizer from a Nitrifying Acid Soil. Proceedings of the National Academy of Sciences of the United States of America, 108, 15892-15897. http://dx.doi.org/10.1073/pnas.1107196108

[19] Lehtovirta, L.E., Prosser, J.I. and Nicol, G.W. (2009) Soil pH Regulates the Abundance and Diversity of Group 1.1c Crenarchaeota. FEMS Microbiology Ecology, 70, 367-376. http://dx.doi.org/10.1111/j.1574-6941.2009.00748.x

[20] Ying, J.Y., Zhang, L.M. and He, J.Z. (2010) Putative Ammonia-Oxidizing Bacteria and Archaea in an Acidic Red Soil 
with Different Land Utilization Patterns. Environmental Microbiology Reports, 2, 304-312. http://dx.doi.org/10.1111/j.1758-2229.2009.00130.x

[21] Rowe, O.F., Sánchez-España, J., Hallberg, K.B. and Johnson, D.B. (2007) Microbial Communities and Geochemical Dynamics in an Extremely Acidic, Metal-Rich Stream at an Abandoned Sulfide Mine (Huelva, Spain) Underpinned by Two Functional Primary Production Systems. Environmental Microbiology, 9, 1761-1771. http://dx.doi.org/10.1111/j.1462-2920.2007.01294.x

[22] Kato, S., Itoh, T. and Yamagishi, A. (2011) Archaeal Diversity in a Terrestrial Acidic Spring Field Revealed by a Novel PCR Primer Targeting Archaeal 16S rRNA Genes. FEMS Microbiology Letter, 319, 34-43. http://dx.doi.org/10.1111/j.1574-6968.2011.02267.x

[23] Pratscher, J., Dumont, M.G. and Conrad, R. (2011) Ammonia Oxidation Coupled to $\mathrm{CO}_{2}$ Fixation by Archaea and Bacteria in an Agricultural Soil. Proceedings of the National Academy of Sciences of the United States of America, 108, 4170-4175. http://dx.doi.org/10.1073/pnas.1010981108

[24] Jung, M.Y., Park, S.J., Min, D., Kim, J.S., Rijpstra, W.I., Sinninghe Damste, J.S., et al. (2011) Enrichment and Characterization of an Autotrophic Ammonia-Oxidizing Archaeon of Mesophilic Crenarchaeal Group I.1a from an Agricultural Soil. Applied Environmental Microbiology, 77, 8635-8647. http://dx.doi.org/10.1128/AEM.05787-11

[25] Treusch, A.H., Leininger, S., Kletzin, A., Schuster, S.C., Klenk, H.P. and Schleper, C. (2005) Novel Genes for Nitrite Reductase and Amo-Related Proteins Indicate a Role of Uncultivated Mesophilic Crenarchaeota in Nitrogen Cycling. Environmental Microbiology, 7, 1985-1995. http://dx.doi.org/10.1111/j.1462-2920.2005.00906.x 
Scientific Research Publishing (SCIRP) is one of the largest Open Access journal publishers. It is currently publishing more than 200 open access, online, peer-reviewed journals covering a wide range of academic disciplines. SCIRP serves the worldwide academic communities and contributes to the progress and application of science with its publication.

Other selected journals from SCIRP are listed as below. Submit your manuscript to us via either submit@scirp.org or Online Submission Portal.
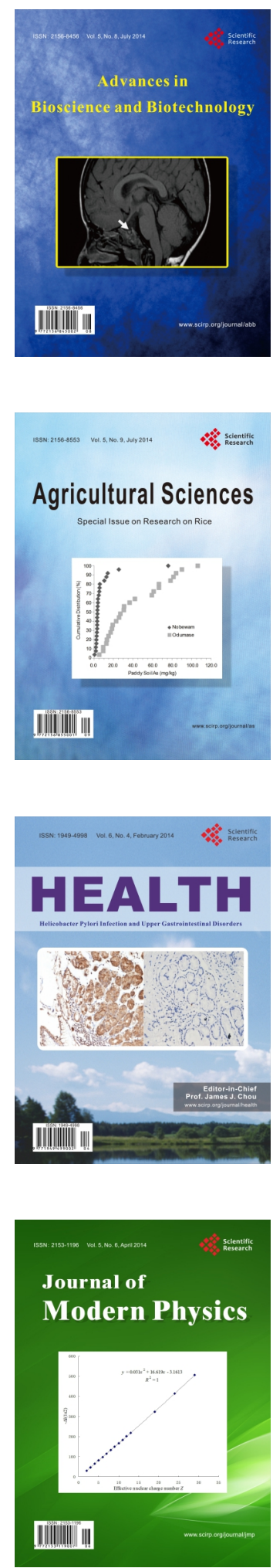
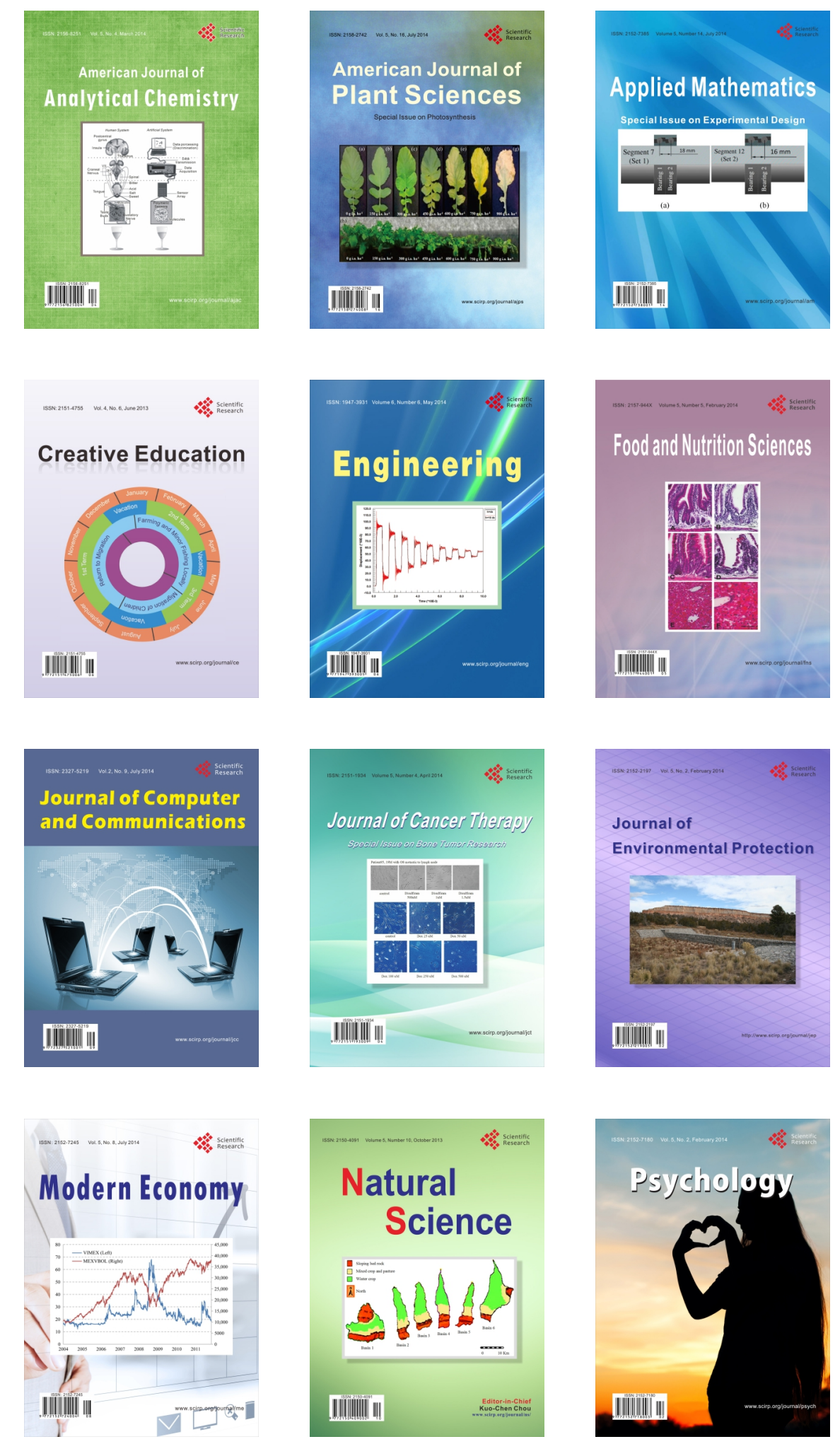